\title{
ANALISIS KEBUTUHAN PARKIR DAN PERANCANGAN LAYOUT PARKIR DENGAN METODE COMPUTERIZED LAYOUT PLANNING (CORELAP) DI UNIVERSITAS KATOLIK DE LA SALLE MANADO
}

\author{
Jordan Kirana Bravo*1, Yulius Ch. Raton ${ }^{2}$, Ronaldo Rottie ${ }^{3}$ \\ 1,2,3 Program Studi Teknik Industri; Fakultas Teknik \\ Universitas Katolik De La Salle Manado; Kombos-Kairagi I Manado, No.Telp:(0431) 871957 \\ E-mail: *1jordankiranabravo@gmail.com, ${ }^{2}$ jraton@ unikadelasalle.ac.id, ${ }^{3}$ rrottie@ unikadelasalle.ac.id
}

\begin{abstract}
Abstrak - Universitas Katolik De La Salle merupakan salah satu perguruan tinggi swasta di Sulawesi Utara. Lokasi yang jauh dari jalan raya membuat akses kendaraan umum menjadi sulit untuk mencapai kampus ini. Terbatasnya akses kendaraan umum untuk ke kampus membuat para mahasiswa, dosen atau staf kampus lebih memilih menggunakan kendaraan pribadi ke kampus maka dari itu kampus membutuhkan area lahan parkir untuk dapat menampung semua kendaraan yang masuk. Tidak adanya layout parkir mebuat kendaraan saling menghalangi akses jalan satu dengan yang lain, karena para pengguna area parkir hanya memarkirkan kedaraan mereka dengan sembarangan. Metode yang digunakan untuk memecahkan permasalahan ini adalah metode perancangan layout yang terdiri dari analisa karakteristik parkir, satuan ruang parkir dari Direktorat Jendral Perhubungan Darat 1996, activity relationship chart, dan algoritma corelap. Data yang didapatkan diolah untuk mengetahui kebutuhan parkir, kemudian mengetahui penataan lahan parkir, dan memberikan hasil akhir berupa layout usulan.
\end{abstract}

Kata kunci-Analisis kebutuhan parkir corelap, layout

Abstract - Universitas Katolik De La Salle Manado is a private University in North Sulawesi. The location that far away from the Main Road make it hard to reach buy public transportation. Limited access for public transportation to reach the campus make students, lectures and the staff prefer to ride their own transportation (car or motorcycle), then the campus should provide the parking space to be able to accommodate all the vehicles that entering the university. Parking area looks stacked and messed up and no parking layout make vehicles hampered to one and other. So this problem will be the base to conduct the research in order find the solution.The method that are used to solve this problem is the the designer method that consisting of Metode analisis karakteristik parkir, satuan ruang parkir From Direktorat Jendral Perhubungan Darat 1996, , activity relationship chart, and corelap algorithm. The objective of the data that have collected is to know the availability of parking area, to know the right parking layout, and to give the final result that is the new lay out.

Keyword: Analisis kebutuhan parkir corelap, layout

\section{PENDAHULUAN}

Masyarakat khususnya pelajar atau mahasiswa datang untuk memperoleh ilmu di salah satu pusat kegiatan masyarakat yaitu perguruan tinggi. Sebagai salah satu institusi pendidikan perguruaan tinggi, jumlah mahasiswa di Universitas Katolik De La Salle mengalami peningkatan. Jumlah mahasiswa di tahun 2015 adalah sebanyak 1.859 mahasiswa pada tahun 2016 jumlah mahasiswa meningkat sebanyak 1.941 mahasiswa, dapat dilihat dari data yang diperoleh dari bagian akademik kampus terjadi penigkatan jumlah mahasiswa sebanyak 82 mahasiswa.

Beberapa tahun terakhir ini volume kendaraan bermotor mulai meningkat di Universitas Katolik De La Salle, dari jumlah data yang didapat dari observasi secara langsung pada bulan April 2017 diketahui bahwa volume kendaraan parkir untuk mobil adalah 240 kendaraan sedangkan untuk motor sebanyak 532 kendaraan. Tidak adanya layout parkir yang menunjukan ruang ketersedian parkir untuk kendaraan membuat area parkir di Universitas Katolik De La Salle terlihat kurang terartur. Para mahasiswa atau staf dan dosen sering memarkirkan kendaraan mereka dengan sembarangan hal ini membuat penumpukan kendaraan diarea parkir. Para penggunaan kendaraan hanya melihat ruang yang kosong yang mereka rasa cukup untuk kendaraan mereka berhenti tanpa memperdulikan kendaraan yang lain, hal ini bisa menyebabkan akses keluar masuk untuk kendaraan menjadi tersumbat. Situasi ini menyebabkan tempat parkir di kampus ini mulai telihat padat.

\subsection{Satuan Ruang Parkir}

\section{TINJAUAN PUSTAKA}

Satuan Ruang Parkir (SRP) merupakan ukuran luas yang efektif untuk meletakan kendaraan. Di dalam SRP juga mencakup ukuran ruang bebas di sisi kendaraan untuk area gerak akses naik turun pengendara atau penumpang, dengan pengertian agar pintu kendaraan dapat dibuka.

Menurut Pedoman Perencanaan dan Pengoperasian Fasilitas Parkir oleh Direktorat Jenderal Perhubungan Darat 1998 (dikutip dalam Palayukan 2015) dalam satuan ruang parkir (SRP) adalah ukuran luas efektif untuk meletakkan kendaraan (mobil penumpang, bus/truk, atau sepeda motor), termasuk ruang bebas dan lebar buka pintu. Untuk menentukan satuan ruang parkir (SRP) didasarkan atas pertimbangan berikut :

1. Dimensi Kendaraan Standar untuk Mobil Penumpang

2. Ruang Bebas Kendaraan Parkir

3. Lebar bukaan pintu kendaraan

Penentuan SRP untuk jenis kendaraan diklasifikasikan menjadi tiga golongan, dapat dilihat pada Tabel 1. [1]

Tabel 1 Penentuan Satuan Ruang Parkir

\begin{tabular}{|c|c|}
\hline Jenis Kendaraan & $\begin{array}{c}\text { Satuan Ruang } \\
\text { Parkir }\end{array}$ \\
\hline $1 . \quad \begin{array}{c}\text { a. Mobil penumpang } \\
\text { untuk golongan I }\end{array}$ & $2,30 \times 5,00$ \\
\hline
\end{tabular}




\begin{tabular}{|c|c|}
\hline Jenis Kendaraan & $\begin{array}{c}\text { Satuan Ruang } \\
\text { Parkir }\end{array}$ \\
\hline b. Mobil penumpang & $2,50 \times 5,00$ \\
untuk golongan II & \\
c. Mobil penumpang & $3,00 \times 5,00$ \\
$\quad$ untuk golongan III & $3,40 \times 12,50$ \\
2. Bus / truk & $0,75 \times 2,00$ \\
3. Sepeda Motor & \\
\hline
\end{tabular}

\subsection{Analisis Kebutuhan Parkir}

Analisis kebutuhan parkir dilakukan untuk mengetahui kebutuhan ruang parkir yang dibutuhkan, menurut Mariani 2010 (dikutip dalam Palayukan 2015) ada beberapa karaksteristik parkir yang perlu diperhatikan untuk mengetahui kebutuhan akan ruang parkir, berikut beberapa karakteristik parkir yang perlu diperhatikan. [1]

\subsubsection{Akumulasi Parkir}

Akumulasi adalah jumlah kendaraan parkir dalam periode waktu tertentu. Akumulasi parkir adalah jumlah keseluruhan yang parkir di suatu tempat pada waktu tertentu dan dibagi sesuai dengan kategori jenis maksud perjalanan. Dimana integrasi dari akumulasi parkir selama periode tertentu menunjukkan beban parkir (jumlah kendaraan parkir) dalam satuan jam kendaraan per periode waktu tertentu. [1]

Data akumulasi parkir dapat disajikan dalam bentuk tabel dan grafik yang memadai, sehingga dapat tergambar akumulasi parkir sesuai dengan kategori maksud perjalanan. Nilai akumulasi parkir tidak sama pada suatu tempat dengan tempat yang lain dari waktu ke waktu. Pada saat tertentu nilai akumulasi parkir melebihi kapasitas parkir yang tersedia dan pada saat lain nilainya di bawah kapasitas parkir yang tersedia (Patihawa, 2014). [2]

Perhitungan akumulasi parkir dapat menggunakan persamaan:

$$
\text { Akumulasi }=\mathrm{Km}-\mathrm{Kk}
$$

Bila pada pengambilan data sudah ada kendaraan parkir, maka:

$$
\text { Akumulasi }=\mathrm{Km}-\mathrm{Kk}+\mathrm{x}
$$

Keterangan:

$\mathrm{Km}=$ Kendaraan yang masuk lokasi parkir

$\mathrm{Kk}=$ Kendaraan yang keluar lokasi parkir

$\mathrm{X}=$ Jumlah kendaraan yang telah parkir sebelum pengamatan.

\subsubsection{Volume Parkir}

Volume parkir adalah jumlah kendaraan yang selang waktu tertentu. Volume parkir adalah jumlah kendaraan yang termasuk dalam beban parkir (yaitu jumlah kendaraan per periode waktu tertentu). Berikut rumus yang digunakan untuk mengetahui volume parkir menurut Hobbs 1995 (dikutip dalam Patihawa 2014). [2]

$$
\text { Volume }=\text { Nin }+\mathrm{X} \text { (kendaraan })
$$

Keterangan:

Nin = Jumlah kendaraan yang masuk
$\mathrm{X}=$ Kendaraan yang sudah ada sebelum waktu survey

\subsubsection{Durasi Parkir}

Durasi parkir adalah informasi yang sangat dibutuhkan untuk mengetahui lama suatu kendaraan parkir. Informasi ini diketahui dengan cara mengamati waktu kendaraan tersebut masuk dan waktu kendaraan tersebut keluar. Durasi atau lamanya parkir diperoleh dengan cara mencari selisih waktu antara waktu saat kendaraan meninggalkan lokasi parkir dan waktu saatkendaraan memasuki pelataran parkir. Berikut rumus untuk mengetahui durasi parkir menurut Hobbs 1995 (dikutip dalam Patihawa 2014). [2]

$$
\text { Durasi }=\text { tout } \text { t } \text { in }
$$

Keterangan :

tout $=$ waktu saat kendaraan masuk lokasi parkir

tin = waktu saat kendaraan keluar lokasi parkir

\subsubsection{Rumus Kebutuhan Parkir}

Berikut adalah rumus untuk mengetahui jumlah kebutuhan ruang parkir yang dibutuhkan, menurut Hobbs 1995 (dikutip dalam Patihawa 2014). [2]

Keterangan :

$$
Z=\frac{Y \times D}{T}
$$
$\mathrm{Z}=$ Ruang parkir yang dibutuhkan (SRP Kendaraan)
$\mathrm{Y}=$ Jumlah kendaraan yang parkir dalam suatu waktu
$\mathrm{T}=$ Lamanya survei (jam)
$\mathrm{D}=$ Rata-rata durasi (jam)

\subsection{Activity Relationship Chart (ARC)}

Menurut Samsudin dan Afma (2014) Activity Relationship Chart atau Peta Hubungan Kerja kegiatan adalah aktifitas atau kegiatan antara masing - masing bagian yang menggambarkan penting tidaknya kedekatan ruangan. Dalam suatu organisasi pabrik harus ada hubungan yang terikat antara suatu kegiatan dengan kegiatan lainnya yang dianggap penting dan selalu berdekatan demi kelancaran aktifitasnya. [3] Oleh karena itu dibuatlah suatu peta hubungan aktifitas, dimana akan dapat diketahui bagaimana hunbungan yang terjadi dan harus dipenuhi sesuai dengan tugas-tugas dan hubungan yang mendukung. Adapun Manfaat ARC yaitu:

a. Menunjukkan hubungan satu kegiatan dengan yang lainnya serta alasannya.

b. Memperoleh suatu landasan bagi penyusunan daerah selanjutnya

Pada dasarnya Activity Relationship Chart ini hampir sama dengan Form to Chart, hanya saja di sini analisisnya bersifat kualitatif. Kalau dalam From to Chart analisis dilaksanakan berdasarkan angka-angka berat/volume dan jarak perpindahan bahan dari satu departemen kedepartemen yang lain. Maka Activity Relationship ini akan menggantikan kedua hal tersebut dengan kode-kode huruf yang akan menunjukan derajat hubungan aktivitas secara 
kualitatif dan juga kode angka yang akan menjelaskan alasan untuk pemilihan kode huruf tersebut.

Di sini kode huruf seperti A ,E, I dan seterusnya menunjukan bagaimana aktivitas dari masing- masing departemen tersebut akan mempunyai hubungan secara langsung atau erat kaitannya satu sama lain.

Tabel 2.Kode diagram ARC

\begin{tabular}{|l|l|}
\hline \multicolumn{1}{|c|}{ Kode } & Deskripsi \\
\hline A & Absolutely Important \\
\hline E & Especially Important \\
\hline $\mathrm{I}$ & Important \\
\hline $\mathrm{O}$ & Ordinary Important \\
\hline $\mathrm{U}$ & Unimportant \\
\hline $\mathrm{X}$ & Undesirable \\
\hline
\end{tabular}

\subsection{Algoritma CORELAP}

Adapun pemecahan masalah dengan algoritma CORELAP dilakukan dengan langkah-langkah sebagai berikut: [4]

a. Pilih salah satu departemen dengan Total Closeness Rating maksimum. Jika terdapat departemen yang memiliki nilai Total Closeness Rating tertinggi yang sama maka pilih salah satu yang memiliki lebih banyak A.

b. Departemen yang dialokasikan kedua, pilih departemen yang mempunyai hubungan A dengan departemen yang telah terpilih. Jika terdapat beberapa maka pilih yang mempunyai Total Closeness Rating terbesar. Jika tidak ada yang mempunyai hubungan $\mathrm{A}$, pilih departemen yang mempunyai hubungan $\mathrm{E}$ dengan departemen yang terpilih.

c. Untuk departemen selanjutnya dipilih yang memiliki hubungan A, E, I, O, U dengan departemen terpilih kedua, atau ketiga dan yang terakhir ditempatkan jika terdapat hubungan $\mathrm{X}$ dengan departemen terpilih pertama. Jika terdapat beberapa pilihan yang mempunyai hubungan yang sama lihat dari nilai Total Closeness Rating yang paling besar, jika masih sama lihat ukuran luas departemen terbesar. Adapun cara Pengalokasian stasiun kerja adalah dengan menggunakan metode sisi barat (western-edge). Departemen yang terpilih pertama kali (urutan pertama) dialokasikan di pusat dari diagram kotak pada Gambar di bawah ini.

\begin{tabular}{|c|c|c|}
\hline 8 & 7 & 6 \\
\hline 1 & $?$ & 5 \\
\hline 2 & 3 & 4 \\
\hline
\end{tabular}

Gambar 1 Diagram Penempatan Stasiun Kerja

Pada gambar diatas, nomor 1 selalu untuk lokasi (kotak) pada sisi terbarat dari departemen - departemen yang telah dialokasikan. Kotak tepat bersebelahan dengan departemen yang telah dialokasikan dalam arah vertikal/horisontal mempunyai bobot penuh sesuai dengan nilai kedekatan dari lokasi yang akan ditentukan dan lokasi sebelumnya. Kotak yang tepat bersebelahan dengan departemen yang telah dialokasikan dalam arah diagonal mempunyai bobot $0,5 \times$ nilai kedekatan dari lokasi yang akan ditentukan dan lokasi sebelumnya. Posisi 1, 3, 5 atau 7, secara penuh bersebelahan dengan nomor 0 (awal) dan posisi 2, 4, 6 atau 8, secara parsial bersebelahan. Departemen yang baru ditempatkan ditentukan berdasar pada WP (Weighted Placement) yang terbesar. Untuk setiap posisi Weighted Placement adalah penjumlahan dari nilai numerik setiap pasangan dari departemen yang berdekatan.

\subsection{Diagram Alir Penelitan}

\section{METODOLOGI PENELITIAN}

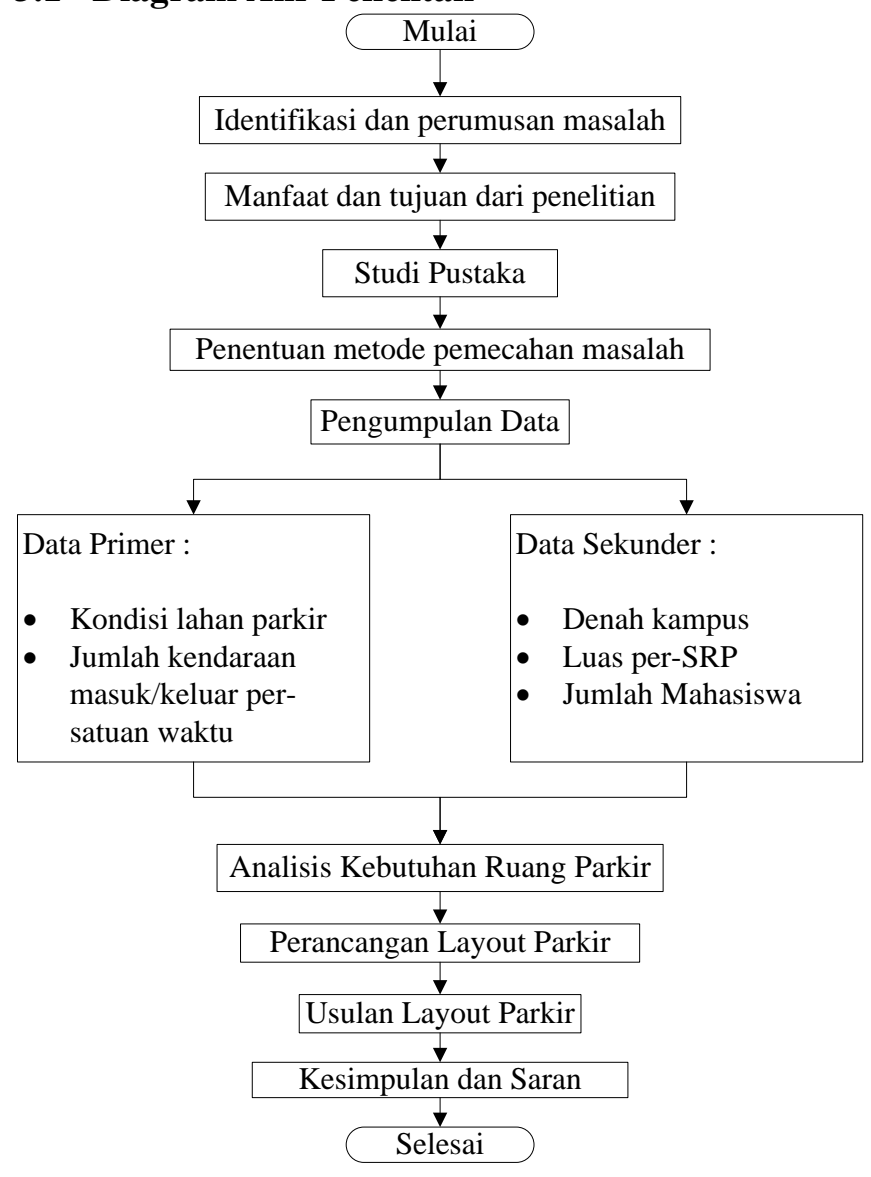

\subsection{DATA}

Gambar 2 Diagram Penempatan Stasiun Kerja

Tahap selanjutnya setelah menentukan metode pemacahan masalah adalah pengumpulan data. Data - data yang akan dikumpulkan merupakan data yang terkait dengan metode yang akan digunakan pada penelitan ini yang nantinya akan dioalah menggunakan metode ini. Pengumplan data pada penelitian ini terbagi menjadi dua yaitu data primer dan data sekunder. Beikut merupakan penjelasan tentang data primer dan data sekunder:

1. Data primer adalah data yang didapatkan peneliti secara langsung (tangan pertama) dari bahan penelitian yang berisikan tentang infromasi dari data yang akan digunakan dalam penelitian. Pada penelitian data primer yang diambil secara langsung melalui observasi yang dilakukan adalah kondisi lahan parkir, luas area lahan parkir dan 
jumlah kendaraan keluar masuk area Universitas Katolik De La Salle per satuan waktu.

2. Data sekunder adalah data yang diperoleh secara tidak langsung atau melalui perantara atau pihak yang sudah memiliki data dari objek penelitan tersebut. Data sekunder umumnya berupa catatan historis, bukti yang sudah dikomentasikan berupa arsip dari data - data yang dipubilkasikan ataupun tidak dipunlikasikan. Data sekunder juga dapat diambil dari sumber yang dicari secara online. Data sekunder dalam penelitian ini adalah denah dari kampus De La Salle, jumlah mahasiswa, dan standar dari luas SRP yang sudah ditentukan oleh direkotorat jendral perhubungan darat.

Pada tabel dibawah bisa dilihat data-data yang dikumpulkan termasuk jenis sumber dan cara pengambilan data.

Tabel 3 DATA

\begin{tabular}{|l|l|l|}
\hline Data & $\begin{array}{l}\text { Jenis dan sumber } \\
\text { data }\end{array}$ & $\begin{array}{l}\text { Cara pengambilan } \\
\text { data }\end{array}$ \\
\hline $\begin{array}{l}\text { Kondisi Lahan } \\
\text { Parkir }\end{array}$ & $\begin{array}{l}\text { Primer } \\
\text { (Fisik/Kualitatif) }\end{array}$ & $\begin{array}{l}\text { Observasi langsung } \\
\text { ke lapangan }\end{array}$ \\
\hline $\begin{array}{l}\text { Luas area } \\
\text { lahan parkir }\end{array}$ & Primer (Kuantitatif) & $\begin{array}{l}\text { Observasi langsung } \\
\text { ke lapangan }\end{array}$ \\
\hline $\begin{array}{l}\text { Jumlah } \\
\text { kendaraan } \\
\text { keluar masuk }\end{array}$ & Primer (Kuantitatif) & $\begin{array}{l}\text { Mencatat jam masuk } \\
\text { dan keluar } \\
\text { kendaraan dan } \\
\text { melakukan check list } \\
\text { kendaraan yang } \\
\text { keluar masuk. yan }\end{array}$ \\
\hline $\begin{array}{l}\text { Denah } \\
\text { Kampus }\end{array}$ & $\begin{array}{l}\text { Sekunder } \\
\text { (Kualitatif) }\end{array}$ & Inoogle Maps \\
\hline SRP & $\begin{array}{l}\text { Sekunder } \\
\text { (Kuantitatif) }\end{array}$ & Internet \\
\hline
\end{tabular}

\subsection{Analisis Kebutuhan Parkir}

Dengan menggunakan pendekatan rumus yang dipelajari maka kita akan menghitung kebutuhan parkir dengan menggunakan rumus :

Dimana :

$$
Z=\frac{\mathrm{Y} \times \mathrm{D}}{\mathrm{T}}
$$

$\mathrm{Z}=$ Kebutuhan Parkir (Satuan Ruang Parkir)

$\mathrm{Y}=$ Rata-rata Volume Parkir

$\mathrm{D}=$ Rata-rata durasi parkir

$\mathrm{T}=$ Waktu pengamatan

Untuk rata-rata durasi parkir bisa kita dapatkan dengan menjumlahkan seluruh durasi rata-rata perhari kemudian dibagi lamanya hari penelitian yaitu sebanyak 5 hari. Dari hasil kalkulasi didapatkan bahwa rata - rata durasi parkir adalah sebesar 163.024 menit atau sama dengan 2,71 jam.

Untuk rata-rata volume parkir didapatkan dengan cara menjumlahkan keselurahan volume parkir selama 5 hari penelitian kemudian dibagai dengan lamanya hari penelitian yaitu 5 hari. Dari hasil kalkulasi didapatkan bahwa rata rata volume parkir adalah sebesar 233.2 kendaraan dibulatkan menjadi 234 kendaraan.
Dari data diatas kita bisa mendapatkan kebutuhan parkir untuk kawasan Universitas Katolik De La Salle Manado berikut perhitungannya,

$$
\begin{aligned}
& Z=\frac{234 \times 2.71}{8} \\
& Z=\frac{635.79}{8} \\
& Z=79.47 \mathrm{SRP}
\end{aligned}
$$

Hasil perhitungan menunjukan bahwa kebutuhan ruang parkir mobil untuk kawasan parkir mobil adalah sebesar 79.47 SRP atau dibulatkan menjadi 80 SRP. Sedangkan untuk motor karena kurangnya kelengkapan data maka kita dapat menggunakan nilai dari akumulasi parkir terbesar sebagai asumsi sementara untuk pengaturan layout parkir, dengan demikian kebutuhan ruang parkir untuk motor adalah sebesar 175 SRP.

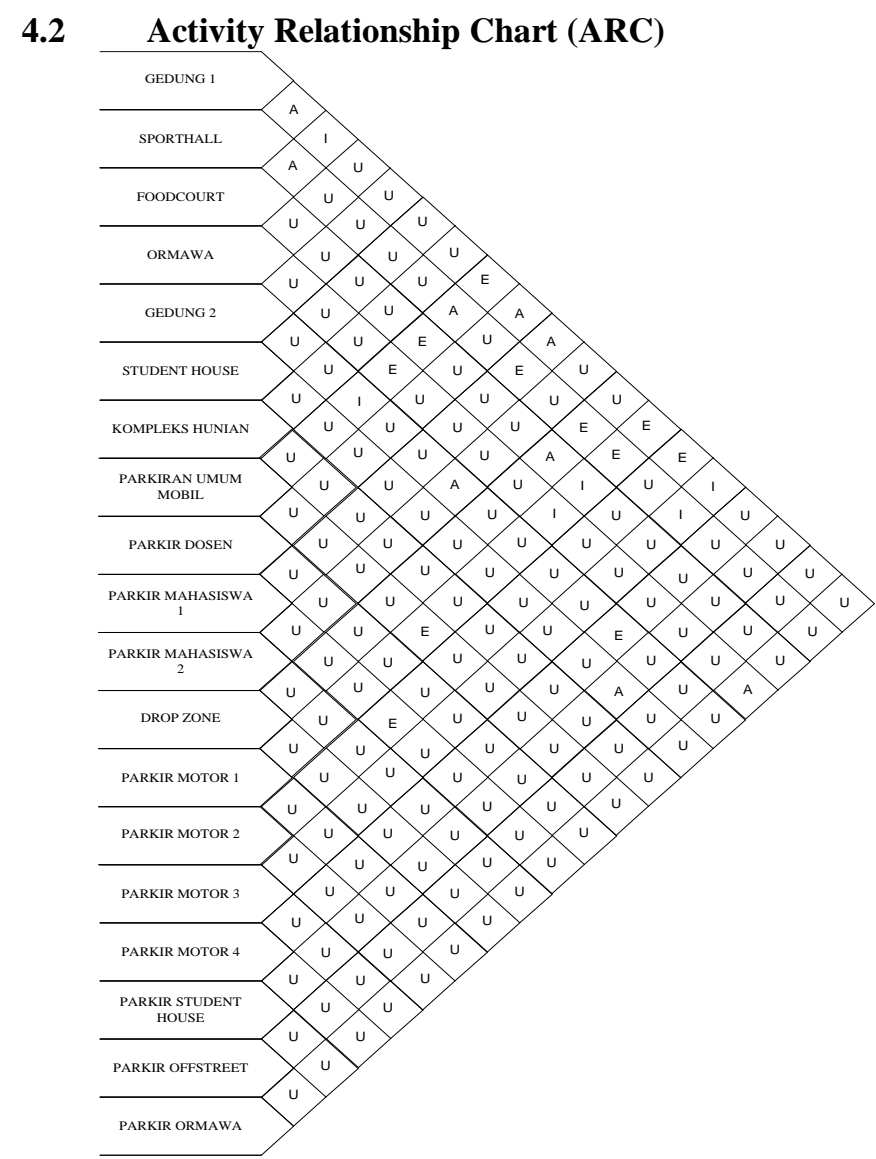

Gambar 3. ARC Layout Plan

1. Analisis parkiran umum mobil

Dari diagram di atas bisa kita lihat bahwa adanya tingkat kedekatan yang tinggi dengan nilai indeks A untuk parkiran umum dengan sporthall dikarenakan lahan parkir terluas yang berada disebelah kiri gedung sporthall. Juga memiliki kedekatan dengan nilai indeks E terhadap foodcourt, parkiran motor 1, gedung 1, dan juga ORMAWA dikarenakan sifat parkiran yang umum. Parkiran umum lebih dikhususkan penggunaannya untuk dosen dan para staf yang tida kebagian ruang parkir di parkiran dosen. Parkir umum mendapatkan indeks $U$ untuk area yang lainnya karena tidak memiliki keterkaitan penting dengan area yang lain. 
2. Analisis parkiran dosen

Dari diagram diatas parkiran dosen mendapat indeks A terhadap Gedung 1, dikarenakan ruang dosen dan pusat kegiatan/kerja berada di Gedung 1. Parkiran dosen tidak memiliki keterkaitan penting dengan area yang lainnya sehingga mendapatkan indeks $U$ untuk area yang lain.

3. Analisis parkiran mahasiswa 1

Dari diagram diatas bisa dilihat bahwa parkiran mahasiswa 1 mendapat Indeks A terhadap Gedung 1 karena adanya kegiatan perkuliahan untuk beberapa mahasiswa di Gedung 1. Parkiran mahasiswa 1 mendapat Indeks E terhadap sporthall dan parkir motor 2 karena adanya lahan parkir yang bisa dimanfaatkan sebagai tempat parkir mobil. Parkiran mahasiswa 1 tidak memiliki keterkaitan yang penting dengan area yang lainnya sehingga mendapatkan indeks $U$ untuk area yang lain.

4. Analisis parkiran motor 1

Dari diagram diatas parkiran motor 1 mendapat indeks $\mathrm{E}$ untuk Gedung 1 dan parkiran umum mobil karena lahan yang disediakan cukup memadai untuk menjadi parkiran motor umum utama. Parkiran motor 1 mendapat indeks I dengan ORMAWA karena gedung ORMAWA tidak memiliki area parkiran motor. Parkiran motor 1 mendapat indeks I dengan foodcourt karena adanya pekerja kantin yang menggunakan motor dan juga untuk para pengunjung Universitas Katolik De La Salle Manado yang mau istirahat makan di foodcourt. Parkiran mahasiswa 2 tidak memiliki keterkaitan yang penting dengan area yang lainnya sehingga mendapatkan indeks I untuk area yang lain.

5. Analisis parkiran mahasiswa 2

Dari diagram diatas bisa dilihat bahwa parkiran mahasiswa 2 mendapat Indeks A terhadap Gedung 2 karena mayoritas kegiatan perkuliahan untuk beberapa mahasiswa ada di Gedung 2. Parkiran mahasiswa 2 tidak memiliki keterkaitan yang penting dengan area yang lainnya sehingga mendapatkan indeks $U$ untuk area yang lain.

6. Analisis parkiran motor 2

Dari diagram diatas parkiran motor mendapat indeks $\mathrm{E}$ untuk Gedung 1 dan parkir mahasiswa 1 karena adanya lahan kosong yang bisa dimanfaatkan sebagai parkiran untuk staf dan mahasiswa yang memiliki kepentingan di Gedung 1. Parkiran motor 2 tidak memiliki keterkaitan yang penting dengan area yang lainnya sehingga mendapatkan indeks $U$ untuk area yang lain.

7. Analisis parkiran motor 3

Dari diagram diatas parkiran motor mendapat indeks I dengan Gedung 1 karena staf dan mahasiswa yang memiliki kepentingan di Gedung 1 jika mereka tidak mendapatkan tempat parkir di parkiran motor 2 maka bisa motor bisa menggunakan area parkiran motor 3 . Parkiran motor mendapat indeks I untuk sporthall karena jika ada event yang dilaksanakan di sporthall maka para pengguna motor bisa memarkirkan kendaraan mereka di area parkiran motor 3. Parkiran motor 3 tidak memiliki keterkaitan yang penting dengan area yang lainnya sehingga mendapatkan indeks $U$ untuk area yang lain.

8. Analisis parkiran Student House

Dari diagram diatas parkiran Student House mendapat indeks A dengan gedung Student House karena parkiran dibuat untuk penghuni Student House. Secara teknis parkiran Student House bisa dimanfaatkan sebagai area parkiran mobil mahasiswa jika mereka tidak mendapatkan tempat parkir di parkiran mahasiswa 1 dan 2. Parkiran student house tidak memiliki keterkaitan yang penting dengan area yang lainnya sehingga mendapatkan indeks $U$ untuk area yang lain.

9. Analisis parkiran motor 4

Dari diagram diatas parkiran motor 4 mendapat indeks $\mathrm{E}$ terhadap gedung 2 karena keperluan untuk kebutuhan parkiran motor khusus mahasiswa yang melakukan aktifitas di gedung 2. Parkiran motor 4 tidak memiliki keterkaitan yang penting dengan area yang lainnya sehingga mendapatkan indeks $U$ untuk area yang lain.

10. Analisis Parkir ORMAWA

Dari diagram diatas parkiran ORMAWA mendapat indeks A dengan gedung ORMAWA karena parkiran dibuat untuk pengurus organisasi mahasiswa. Parkiran ORMAWA tidak memiliki keterkaitan yang penting dengan area yang lainnya sehingga mendapatkan indeks $\mathrm{U}$ untuk area yang lain.

11. Area Drop Zone

Mendapatkan indeks A dengan Food Court karena kebutuhan persediaan untuk bahan makanan dan minuman berada di Food Court Universitas Katolik De La Salle. Area Drop Zone tidak memiliki keterkaitan yang penting dengan area yang lainnya sehingga mendapatkan indeks $U$ untuk area yang lain.

12. Gedung 1

Mendapatkan indeks A dengan sporthall dan I dengan foodcourt dikarenakan tingkat kepentingan berdasarkan jarak dari tata letak layout awal. Hubungan kedekeatan gedung 1 dengan beberapa area parkir bisa dilihat alasan indeks kedekatan pada analisis di masing-masing parkiran. Gedung 1 tidak memiliki keterkaitan yang penting berdasarkan jarak ataupun fungsi dengan area yang lainnya sehingga mendapatkan indeks $U$ untuk area yang lain.

13. Sporthall

Mendapatkan indeks A dengan foodcourt dan sporthall dikarenakan tingkat kepentingan berdasarkan jarak dari tata letak layout awal. Hubungan kedekeatan sporthall dengan beberapa area parkir bisa dilihat alasan indeks kedekatan pada analisis di masing-masing parkiran. Sporthall tidak memiliki keterkaitan yang penting berdasarkan jarak ataupun fungsi dengan area yang lainnya sehingga mendapatkan indeks $U$ untuk area yang lain.

14. Foodcourt

Mendapatkan indeks A dengan sporthall dan I dengan gedung 1 dikarenakan tingkat kepentingan berdasarkan jarak dari tata letak layout awal. Hubungan kedekeatan foodcourt dengan beberapa area parkir bisa dilihat alasan indeks kedekatan pada analisis di masing-masing 
parkiran. Foodcourt tidak memiliki keterkaitan yang penting berdasarkan jarak ataupun fungsi dengan area yang lainnya sehingga mendapatkan indeks U untuk area yang lain.

15. Gedung 2, ORMAWA, Student House

Hubungan kedekeatan gedung 2, ORMAWA, student house dengan beberapa area parkir bisa dilihat alasan indeks kedekatan pada analisis di masing-masing parkiran. Gedung 2, ORMAWA, student house tidak memiliki keterkaitan yang penting berdasarkan jarak ataupun fungsi dengan area yang lainnya sehingga mendapatkan indeks $U$ untuk area yang lain.

16. Parkir Offstreet dan Kompleks Hunian

Parkir offstreet dan kompleks hunian tidak memiliki keterkaitan yang penting berdasarkan jarak ataupun fungsi dengan semua area sehingga mendapatkan indeks $\mathrm{U}$ untuk semua area.

\subsection{Agortima CORELAP}

Untuk mendapatkan hasil layout plan dengan menggunakan Algoritma CORELAP, maka harus diketahui Total Closeness Rating (TCR) dari data yang didapat dari diagram ARC. Berikut nilai TCR untuk tiap simbol ARC,

Tabel 4 Tabel Nilai TCR

\begin{tabular}{|c|l|l|}
\hline Simbol & \multicolumn{1}{|c|}{ Deskripsi } & \multicolumn{1}{c|}{ TCR } \\
\hline $\mathrm{A}$ & Absolutelly Important & 10000 \\
\hline $\mathrm{E}$ & Espcially Important & 1000 \\
\hline $\mathrm{I}$ & Important & 100 \\
\hline $\mathrm{O}$ & Ordinary Important & 10 \\
\hline $\mathrm{U}$ & Unimportent & 0 \\
\hline $\mathrm{X}$ & Undesireable & -10 \\
\hline
\end{tabular}

Berikut adalah perhitungan TCR untuk dapat lebih mudah melihat area dan hasil perhitungan maka dibuat kode untuk setiap area aktifitas seperti dibawah ini.

Tabel 5 Kode Area 2

\begin{tabular}{|l|l|}
\hline Area & Kode \\
\hline Gedung 1 & a \\
\hline SportHall & b \\
\hline Food Court & c \\
\hline ORMAWA & d \\
\hline Gedung 2 & e \\
\hline Student House & f \\
\hline Kompleks Hunian & g \\
\hline Parkir Umum Mobil & h \\
\hline Parkir Mahasiswa 1 & i \\
\hline Parkir Dosen & j \\
\hline Parkir Mahasiswa 2 & k \\
\hline Drop Zone & l \\
\hline Parkir Motor 1 & $\mathrm{m}$ \\
\hline Parkir Motor 2 & $\mathrm{n}$ \\
\hline Parkir Motor 3 & $\mathrm{o}$ \\
\hline Parkir Motor 4 & p \\
\hline Parkir Student House & $\mathrm{q}$ \\
\hline Parkir Offstreet & $\mathrm{r}$ \\
\hline Parkir Ormawa & $\mathrm{s}$ \\
\hline
\end{tabular}

Setelah pembuatan tabel untuk lebih mudah melihat hubungan antar tiap area aktifitas, berikut akan dilakukan perhitungan untuk mengetahui nilai TCR pada tiap area aktifitas. Perhitungan tiap aktifitas disajikan pada tabel 6

\begin{tabular}{|c|c|c|c|c|c|c|c|c|c|c|c|c|c|c|c|c|c|c|c|}
\hline 엉 & $\begin{array}{l}\text { 이 } \\
\text { ஸ̂ } \\
\text { ભn }\end{array}$ & 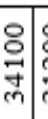 & 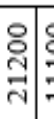 & 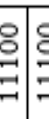 & $\begin{array}{l}8 \\
= \\
=\end{array}$ & & 을 & 응 & 용 & 잉 & 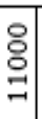 & 일 & ঃి & & 임 & 이잉 & & 잉. & \\
\hline an & $\circ$ & $\circ$ & ० & 이잉 & $\circ 0$ & 0 & 0 & o & 0 & 이 & o & 0 & 이 & $\circ$ & $\circ$ & 0 & 이 & & 응 \\
\hline$H$ & 0 & 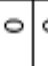 & $\circ$ & $\circ \circ$ & $\circ \circ$ & 0 & 0 & o & 0 & 이 & $\circ$ & o & 이 & 이 & - & 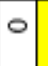 & & 이 & 0 \\
\hline$\sigma$ & $\circ$ & 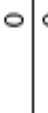 & $\circ$ & $\circ$ & 이이 & 5. & 0 & 0 & $\circ$ & 이 & 0 & 이 & ㅇ & 이 & 이 & & 이 & 인 & 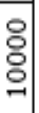 \\
\hline إه & 0 & 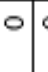 & $\circ$ & $\circ$ & $8^{\circ}$ & 0 & $\circ$ & o & 이 & 이 & o & 이 & 이 & 이 & & 이 & 이 & $\circ$ & 응 \\
\hline$\circ$ & : & 이 & $\circ$ & $\circ c$ & $\circ \mid 0$ & 0 & 잉 & 0 & $\circ$ & 이 & 0 & 0 & - & & $\circ$ & 0 & 인 & $\circ$ & ర్ల \\
\hline$\Rightarrow$ & 잉. & 잉 & $\circ$ & $\circ c$ & $\circ 0$ & 0 & 0 & & 응 & 이 & 인 & 이 & & $\circ$ & 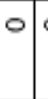 & 이 & 이 & $\circ$ & 잉 \\
\hline 吕 & 잉. & 잉. & 익 & & $\circ 0$ & 0 & 잉 & 이 & 이 & 이 & 인 & & 이 & $\circ$ & $\circ$ & 이 & 이 & $\circ$ & 융 \\
\hline$\rightarrow$ & $\circ$ & 일 & 잃 & $\circ c$ & 0 & 0 & 잉 & 0 & 0 & 이 & & 이 & ㅇ & $\circ$ & - & o & 이 & ㅇ & $\stackrel{\circ}{\circ}$ \\
\hline s4 & 0 & 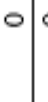 & $\circ 0$ & $\circ$ & : & 0 & 0 & o & $\circ$ & & 이 & 이 & ㅇ & $\circ$ & - & o & 이 & 0 & 응 \\
\hline & ঃ & 임 & $\circ 0$ & $\circ c^{\circ}$ & 00 & 0 & 0 & 이 & & 이 & $\circ$ & & 잉 & 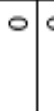 & $\circ$ & 이 & 이 & ㅇ & $\begin{array}{l}\text { 음 } \\
\text { 기 }\end{array}$ \\
\hline & 이이 & & $\circ 0$ & $\circ 0$ & 0 & 0 & 0 & & 이 & 이 & 0 & 0 & ㅇ & - & - & 0 & 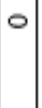 & 이 & 응 \\
\hline 다 & 잉 & 이이 & ঃํㅀ & 일 & 80 & 0 & & 이 & 0 & 이 & 0 & 잉 & - & $\circ$ & $\circ$ & 0 & 이 & ㅇ & $\begin{array}{l}\stackrel{8}{9} \\
\underset{-}{\mathrm{I}}\end{array}$ \\
\hline$b 0$ & o & 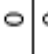 & - & $\circ \circ$ & 0 & & 이 & 이 & 이 & 이 & $\circ$ & 이 & ㅇ & $\circ$ & - & 이 & 이 & 이 & 0 \\
\hline 4 & 0 & 이 & $\circ$ & $\circ$ & ○ & $\circ$ & 0 & 이 & 이 & 이 & 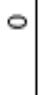 & 0 & 인 & $\circ$ & & 응 & $\circ$ & 이 & 응 \\
\hline$v$ & $\circ$ & 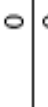 & $\circ \circ$ & 이 & $\circ$ & 0 & 익 & 0 & & 잉 & $\circ$ & - & $\circ$ & & 음 & 0 & 0 & ㅇ & $\begin{array}{l}\text { 을 } \\
\Xi \\
=\end{array}$ \\
\hline ס & 0 & 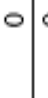 & 이 & c & $\circ \circ$ & 0 & 응 & 0 & 0 & 이 & $\circ$ & 임 & ㅇ & $\circ$ & - & 0 & 이 & 잃 & $\stackrel{ }{\stackrel{\circ}{g}}$ \\
\hline 0 & 익. & 잃 & & $\circ c^{\circ}$ & $\circ \circ$ & 0 & 응 & 0 & $\circ$ & 이 & 응 & 음 & ㅇ & - & - & o & 이 & 이 & $\begin{array}{l}\text { 워 } \\
\text { ते }\end{array}$ \\
\hline قـ & 잉 & & ঃి & $\circ 0$ & $\circ \circ$ & & $\begin{array}{l}\circ \\
\\
\end{array}$ & & 응 & 이 & 임 & 잉. & 응 & $\circ$ & $\circ$ & - & 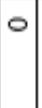 & 이 & 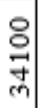 \\
\hline तf & & 잉. & 음 & & $\circ \circ$ & & 잉 & 응 & 잉 & 이 & $\circ$ & 잉. & 잉 & $\stackrel{-}{\circ}$ & & 0 & 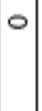 & 이 & $\begin{array}{l}\text { 얼 } \\
\text { ભn } \\
\text { m. }\end{array}$ \\
\hline & & & 07 & $\nabla$ & $\begin{array}{ll}4 & 4-1\end{array}$ & & & $\Rightarrow$ & & $\exists$ & -1 & घ & 7 & & & $\sigma$ & $H$ & a & \\
\hline
\end{tabular}


Menggunakan metode sisi barat (western-edge) maka TCR terbesar akan dialokasikan ditengah diagram. Berdasarkan tabel 4.8 TCR terbesar adalah area sporthall (b) sehingga area sporthall yang akan di alokasikan dipusat dari diagram. Berikut adalah contoh perhitungan untuk penentuan lokasi terbaik.

\begin{tabular}{|c|c|c|}
\hline 8 & 7 & 6 \\
\hline 1 & $\mathrm{~b}$ & 5 \\
\hline 2 & 3 & 4 \\
\hline
\end{tabular}

Gambar 4. Diagram penempatan sporthall

Area berikut yang akan dialokasikan adalah area Gedung 1 (a) karena memiliki hubungan kedekatan A dengan sporthall dan memiliki TCR tertinggi untuk derajat $\mathrm{A}$, dengan perhitungan lokasi sebagai berikut.

Jika gedung 1 (a) di :

Lokasi $1,3,5,7$ bernilai $=1 \times 10000=10000$

Lokasi $2,4,6,8$ bernilai $=0.5 \times 10000=5000$

Dari perhitungan diatas diketahui bahwa gedung 1 (a) memiliki nilai weighted position sebesar 10000 untuk lokasi 1,3,5,7, sedangkan untuk lokasi 2,4,6,8 nilai wheigthed position untuk gedung 1 (a) sebesar 5000. Ada 4 lokasi yang bisa digunakan memposisikan gedung 1 , pada kasus ini Gedung 1 (a) akan dialokasikan di lokasi 1 dengan alasan untuk menyesuaikan dengan tata letak gedung yang sudah ada.

Hasil dari perhitungan dari seluruh area yang akan dialokasikan dapat dilihat pada lampiran 3. Berikut adalah hasil akhir dari perhitungan lokasi untuk 19 area yang terdapat di Universitas Katolik De La Salle Manado dengan menggunakan algoritama CORELAP secara manual.

\begin{tabular}{|c|c|c|c|c|c|}
\hline & & & $\mathrm{k}$ & $\mathrm{f}$ & $\mathrm{q}$ \\
\hline & $\mathrm{S}$ & d & $\mathrm{e}$ & $\mathrm{p}$ & \\
\hline & $\mathrm{m}$ & $\mathrm{h}$ & 1 & & \\
\hline $\mathrm{j}$ & $\mathrm{a}$ & b & $\mathrm{c}$ & & \\
\hline $\mathrm{o}$ & $\mathrm{i}$ & $\mathrm{n}$ & $\mathrm{g}$ & $\mathrm{r}$ & \\
\hline
\end{tabular}

Gambar 5. Final Plan Layout

Hasil perhitungan dengan algoritma CORELAP dengan metode western-side didapatkan plant layout untuk lokasi parkir seperti gambar diatas. Keterangan untuk gambar di atas bisa di lihat pada tabel 4.7 Tabel
Kode Area, untuk warna kuning menunjukan area gedung dan untuk warna putih menunjukan area parkir.

\subsection{Gambar Layout Usulan}

Pada penelitian ini gambar akan menggunakan bantuan dari software AUTOCAD yang di run pada laptop SONY VAIO SVE144537 dengan kapasitas RAM sebanyak 4 Giga Bytes (GB). Nilai dari setiap ukuran ruang parkir diambil dari data yang didapatkan dari ketetapan Direktorat Jenderal Perhubungan Darat untuk luas ruang parkir. Berikut adalah gambar usulan layout untuk setiap tempat parkir di UNIKA DE LA SALLE MANADO.

Gambar 6. Parkiran umum mobil (h), Dropzone (l) dan Parkir motor $1(\mathrm{~m})$

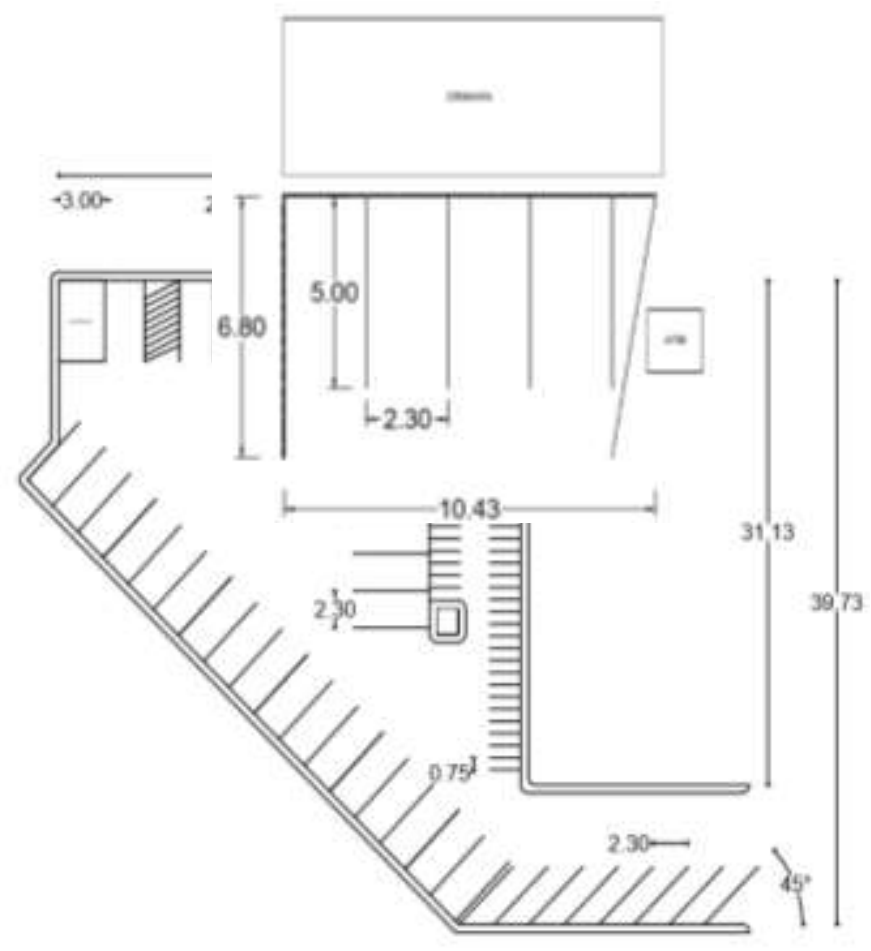

Gambar 7. Parkiran ORMAWA (s)

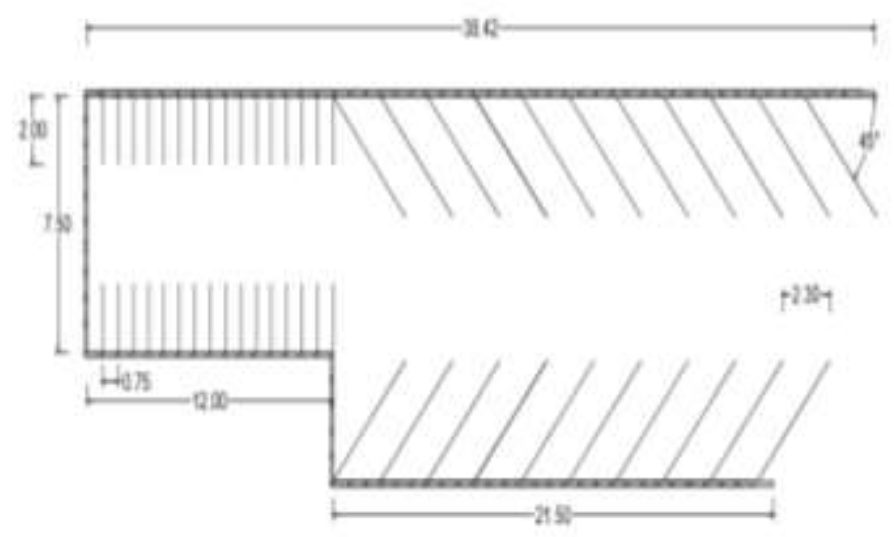


Gambar 8. Parkiran Mahasiswa 1 (i) dan Parkir Motor 2

(n)

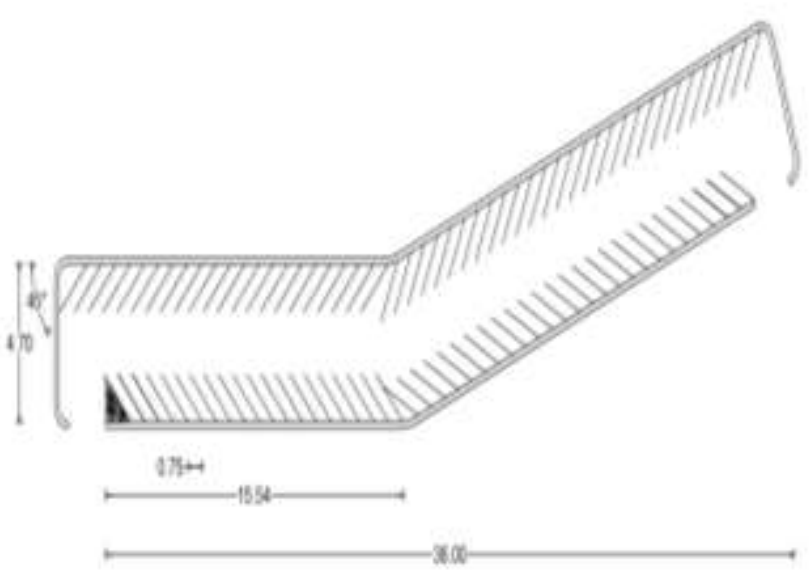

Gambar 9.Parkir Motor 3

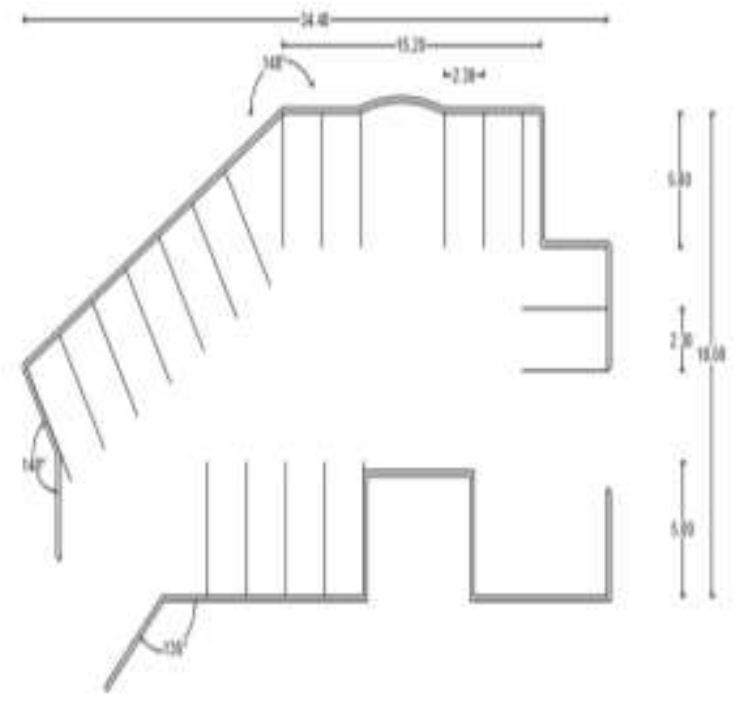

Gambar 10. Parkiran Dosen

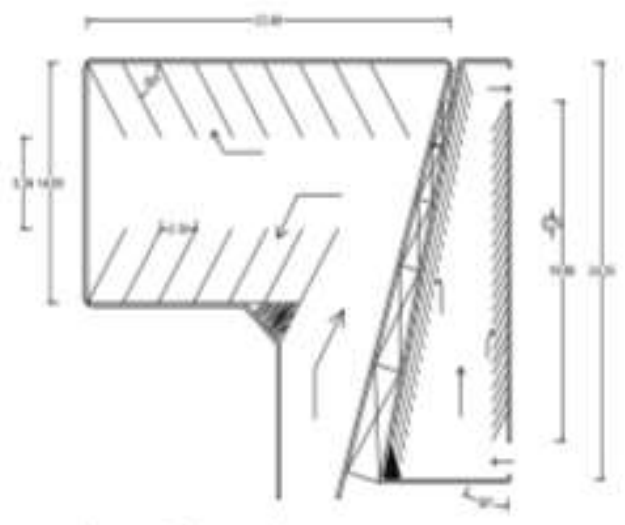

36

Gambar 11. Parkir Mahasiswa 2 dan Parkir Motor 4

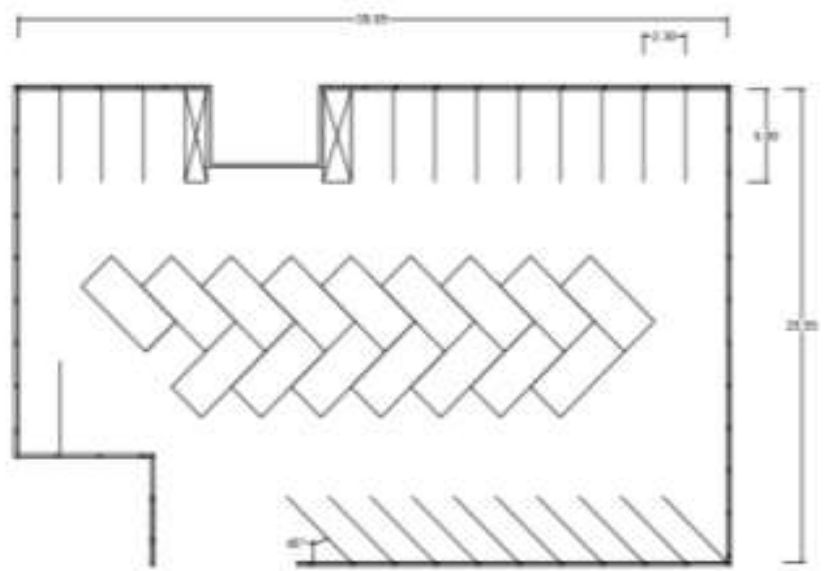

Gambar 4.13 Parkiran Student House

\subsection{Perbandingan Layout Existing dan Layout Usulan}

Lebih jelasnya lagi perbandigan antara layout exisiting dan layout usulan dapat dilihat pada tabel di bawah ini.

Tabel 4.10 Perbandingan Layout

\begin{tabular}{|c|c|}
\hline Layout Existing & Layout Usulan \\
\hline 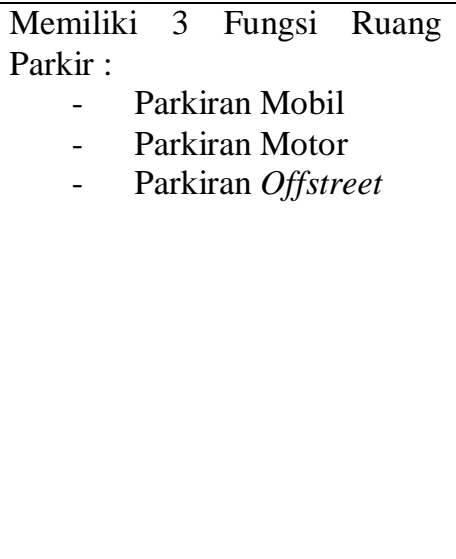 & $\begin{array}{cl}\text { Memiliki } 12 \text { Fungsi Parkir : } \\
\text { - } & \text { Parkir Umum Mobil } \\
\text { - } & \text { Parkir Mahasiswa 1 } \\
\text { - } & \text { Parkir Dosen } \\
\text { - } & \text { Parkir Mahasiswa 2 } \\
\text { - } & \text { Drop Zone } \\
\text { - } & \text { Parkir Motor 1 } \\
\text { - } & \text { Parkir Motor 2 } \\
\text { - } & \text { Parkir Motor 3 } \\
\text { - } & \text { Parkir Motor 4 } \\
\text { - } & \text { Parkir Student } \\
& \text { House } \\
\text { - } & \text { Parkir Offstreet } \\
\text { - } & \text { Parkir Ormawa }\end{array}$ \\
\hline 61 SRP Mobil & 130 SRP Mobil \\
\hline 110 SRP Motor & 240 SRP Motor \\
\hline 8 lahan parkir & 12 lahan parkir \\
\hline
\end{tabular}

\section{KESIMPULAN}

Beberapa kesimpulan yang dapat diambil dari pembahasan sebelumnya mengenai perancangan layout parkir pada Universitas Katolik De La Salle Manado, antara lain:

1. Hasil dari perhitungan kebutuhan ruang parkir dengan metode SRP di Universitas Katolik De La Salle Manado adalah sebanyak 80 SRP, sedangkan untuk motor diasumsikan sebesar 175 SRP dengan mengambil jumlah akumulasi parkir tertinggi. 
2. Perhitungan dengan menggunakan algoritma corelap mendapatkan hasil plan layout yang bisa dilihat pada gambar 4.7 Final Plan Layout

3. Berdasarkan hasil gambar dari layout parkir di Universitas Katolik De La Salle Manado diketahui, jumlah ruang parkir untuk mobil yang dapat ditampung adalah sebanyak 130 SRP dengan demikian kebutuhan parkir untuk mobil dinyatakan cukup karena kebutuhan ruang parkir yang dibutuhkan adalah 80 SRP untuk mobil. Sedangkan untuk motor sebanyak 240 SRP dimana kebutuhan ruang parkir yang diasumsikan sebanyak 175 SRP (lebih kecil dari pada ruang parkir yang tersedia

\section{DAFTAR PUSTAKA}

[1] Palayukan, R. (2015). Analisis Karakteristik Parkir Kendaraan Pada Area Parkir di Bandar Sultan Hassanudin di Kota Makasar.

[2] Patihawa, A. (2014). Evaluasi Kebututhan Parkir Pada Bandar Udara Radin Inten II Branti Lampung Selatan.

[3] Samsudin, M. Afma ,V. (2012). Perancangan Ulang Tata Letak Pabrik Jamur Tiram Menggunakan Metode Activity Relationship Chart Untuk Meningkatkan Produktivitas (Studi Kasus CV. Mandiri Tiban III).

[4] Suhendar, D (2012). Usulan Tata letak Fasilitas Produksi Dengan Algoritma CORELAP. 